\title{
Functional polymorphisms in the promoter region of macrophage migration inhibitory factor and chronic gastritis
}

\author{
TOMIYASU ARISAWA, TOMOMITSU TAHARA, TOMOYUKI SHIBATA, MITSUO NAGASAKA, \\ MASAKATSU NAKAMURA, YOSHIO KAMIYA, HIROSHI FUJITA, MASAHIKO NAKAMURA, \\ DAISUKE YOSHIOKA, YUKO ARIMA, MASAAKI OKUBO, ICHIRO HIRATA and HIROSHI NAKANO
}

Department of Gastroenterology, Fujita Health University School of Medicine, 1-98 Dengakugakubo, Kutsukake-cho, Toyoake 470-1192, Japan

Received May 7, 2007; Accepted June 27, 2007

\begin{abstract}
Macrophage migration inhibitory factor (MIF) is a key proinflammatory mediator, which plays a pivotal role in inflammatory and immune diseases. We attempted to clarify associations of the functional polymorphisms of the MIF gene promoter with the development of chronic gastritis. The study was performed with 290 stocked DNAs from subjects with no evidence of gastric malignancy. We employed the PCRSSCP method to detect gene polymorphisms. The severity of histological chronic gastritis in antral biopsy specimens was classified according to the updated Sydney system. Both the 7/7-CATT repeat at position -794 and the $-173 \mathrm{C} / \mathrm{C}$ genotypes were significantly associated with a risk of developing severe gastric mucosal atrophy (OR, 9.69; 95\% CI, 1.29-72.5; and OR, 4.60; 95\% CI, 1.05-20.2, respectively). In subjects younger than 60 years old, the number of 7-CATT alleles was significantly correlated with both the activity and inflammation scores $(\mathrm{p}=0.0079$ and 0.0080 , respectively). Our results suggested that functional promoter polymorphisms of the MIF gene might be associated with the severity of gastric mucosal inflammation in younger subjects and with the subsequent development of mucosal atrophy.
\end{abstract}

\section{Introduction}

Macrophage migration inhibitory factor (MIF) is a key proinflammatory mediator, which plays a pivotal role in inflammatory and immune diseases (1-5). It contributes toward an excessive inflammatory response both directly via an induction of proinflammatory cytokine secretion (6) and indirectly through its ability to override the anti-inflammatory activity of glucocorticoids (7). MIF has been shown to

Correspondence to: Dr Tomiyasu Arisawa, Department of Gastroenterology, Fujita Health University School of Medicine, 1-98 Dengakugakubo, Kutsukake-cho, Toyoake 470-1192, Japan

E-mail: tarisawa@fujita-hu.ac.jp

Key words: macrophage migration inhibitory factor, promoter polymorphism, chronic gastritis, Helicobacter pylori contribute toward an exaggerated gram-negative response through its ability to induce Toll-like receptor 4 (TLR4), a key receptor responsible for LPS-induced inflammatory cytokine production (8). It is well known that Helicobacter pylori (H. pylori), one of the gram-negative bacterium, colonizes in the human stomach and causes gastric inflammation and peptic ulcer disease. Recently, Xia et al reported that $H$. pylori infection increased MIF expression in both gastric inflammatory and epithelial cells (9), thus MIF may play an important role in $H$. pylori-related gastric inflammation.

Polymorphisms with potential functional relevance have been identified in the MIF gene promoter; an SNP at position -173 (G to C) (10) and a tetranucleotide CATT repeat beginning at nucleotide position -794 (11) have been found to be associated with altered levels of MIF gene transcription in vitro. Although it has been demonstrated that the functional importance of these variants includes a of significant association with several immune-mediated inflammatory diseases (10-12), the role of these polymorphisms in the development of chronic gastritis remains unclear.

In the present study, we attempted to clarify associations of G-173C and -794 CATT repeats in the MIF gene promoter with the development of chronic gastritis.

\section{Materials and methods}

Clinical samples. We randomly selected 300 samples from our stocked DNA from patients who were enrolled at the Endoscopy Center of Fujita Health University Hospital in 2006. All these patients underwent upper gastrointestinal endoscopy, and biopsy specimens were taken from antral mucosa. Part of each specimen was fixed in $10 \%$ buffered formalin and embedded in paraffin, while the other part was immediately frozen and stored at $-80^{\circ} \mathrm{C}$. Finally, the study population comprised 290 subjects with no neoplastic lesions whose DNA was clearly analyzed.

All histological diagnoses were made at the Department of Pathology of our hospital. The severity of chronic gastritis was also classified according to the updated Sydney system (13) by a pathologist who had no access to any clinical information. According to the severity of gastric mucosal atrophy, the subjects were divided into two groups as 
a)

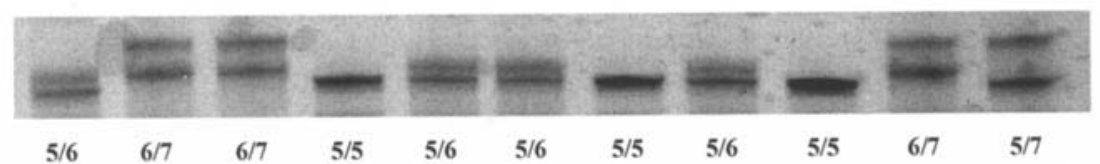

b)

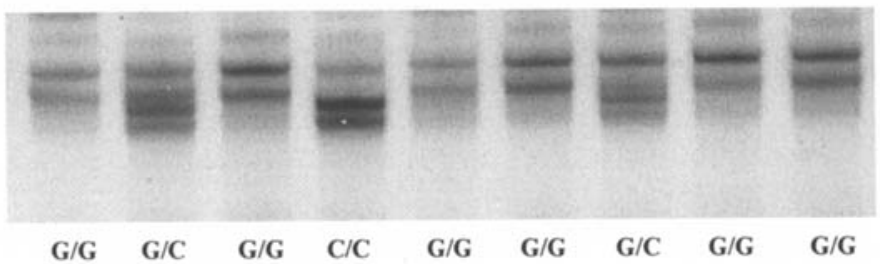

Figure 1. The images of PCR-SSCP using clinical samples. (a) Identification to a tetranucleotide (CATT) repeat (5-7) at position -794. (b) Identification to a base $(\mathrm{G} / \mathrm{C})$ at position -173 .

follows: the severe atrophy (SA) group (atrophy score $\geq 2$ or metaplasia score $\geq 2$ ) and the non-atrophy group (the remaining subjects). H. pylori infection status was assessed by serology, histological examination, or the urea breath test. Patients were diagnosed as having infection when at least one of the diagnostic tests was positive.

The Ethics Committee of Fujita Health University School of Medicine approved the protocol, and written informed consent was obtained from all of the participating subjects.

Genotyping of polymorphisms. Sample stocked DNAs isolated from biopsy specimens or peripheral blood were used. Polymorphism was genotyped by the PCR-SSCP method as reported previously $(14,15)$. To detect -794 CATT repeats, using the primer pair (MIFTR forward: 5'-TGATCC AGTTGCTGCCTTGTC-3', and MIFTR reverse: 5'-TCCA CTAATGGTAAACTCGGGGAC-3'), PCR was carried out in a volume of $20 \mu \mathrm{l}$ containing $0.1 \mu \mathrm{g}$ of genomic DNA. The DNA was denatured at $95^{\circ} \mathrm{C}$ for $3 \mathrm{~min}$, followed by 35 cycles at $95^{\circ} \mathrm{C}$ for $30 \mathrm{sec}, 62^{\circ} \mathrm{C}$ for $40 \mathrm{sec}$, and $72^{\circ} \mathrm{C}$ for $45 \mathrm{sec}$, with final extension at $72^{\circ} \mathrm{C}$ for $5 \mathrm{~min}$. Thereafter, $2 \mu 1$ of the PCR product was denatured with $10 \mu 1$ of formamide (SigmaAldrich Co., St. Louis, USA) at $90^{\circ} \mathrm{C}$ for $5 \mathrm{~min}$. SSCP was carried out at $6^{\circ} \mathrm{C}$ using a GenePhor DNA separation system with GeneGel Excel 12.5/24 (Amersham Biosciences Corp., USA), after which the denatured single-strand DNA bands were detected using a DNA Silver Staining kit (Amersham Biosciences Corp.).

To detect the G-173C polymorphism, using the primer set (MIF173 forward: 5'-TCTAGCCGCCAAGTGGAGAACA3' and MIF173 reverse: 5'-ACTGTGGTCCCGCCTTTTG TGA-3'), the PCR reaction was carried out at a $60^{\circ} \mathrm{C}$ annealing temperature as described above. SSCP was also carried out as described above.

Statistical analysis. The odds ratio (OR) and 95\% confidence intervals (CI) were estimated by logistic regression analysis after adjustment for age, gender and $H$. pylori infection status. The Mann-Whitney $U$ test and linear regression analysis were employed to assess the association between MIF polymorphism and the updated Sydney system scores. For all analyses, the level of significance was set at $\mathrm{p}<0.05$.

\section{Results}

The characteristics of subjects and the frequencies of genotypes. As shown in Fig. 1, single-strand DNAs of both -794 repeats and G-173C were clearly separated by SSCP. A single-strand band of the 8-CATT repeat was not detected in any of the 290 subjects. These polymorphisms were in significant linkage disequilibrium, with the $-173 \mathrm{C}$ allele strongly associated with the 7-CATT repeat allele. The most frequent haplotypes were G·5-CATT, G·6-CATT and C.7CATT, which constituted about $90 \%$ of the haplotypes.

With respect to gastric mucosal atrophy, 103 of the subjects were classified into the SA group (Table I). The male/female ratio was higher in the SA group than in the non-atrophy group. Regarding the H. pylori-positive rate, there was a significant difference between the 2 groups (SA>non-atrophy). The frequencies of n-CATT and -173C alleles were not significantly different between the 2 groups.

The association between the -794 CATT repeats and gastric mucosal atrophy. Overall, infection with H. pylori was strongly associated with the development of gastric mucosal atrophy. By unadjusted analysis, both male gender and the 7/7-CATT genotype were significantly associated with gastric mucosal atrophy, and the 7/7-CATT genotype was also significantly associated after adjustment for age, gender and $H$. pylori infection status (OR, 9.69; 95\% CI, 1.29-72.5; Table II). The frequency of the 5/5-CATT genotype was not associated with the gastric mucosal atrophy. In addition, a significant association between the gastric mucosal atrophy and the $-173 \mathrm{C} / \mathrm{C}$ genotype was found by both unadjusted and adjusted analysis (OR, 2.77; 95\% CI, 1.02-7.50; and OR, 4.60; 95\% CI, 1.05-20.2, respectively; Table III).

The relationship between MIF genotypes and the infiltration of inflammatory cells into gastric mисоsa. As shown in Fig. 2, there was no significant relationship between MIF gene 
Table I. Characteristics of the subjects and frequency of genotypes.

\begin{tabular}{lccc}
\hline & Total & Non-atrophy & Severe atrophy \\
\hline No. of subjects & 290 & 187 & 103 \\
Mean age \pm SD & $60.9 \pm 13.0$ & $59.6 \pm 14.1$ & $63.4 \pm 10.5$ \\
Male:female & $178: 112$ & $101: 86$ & $77: 26$ \\
H.pylori-positive rate & $66.2 \%$ & $48.1 \%$ & $99.0 \%$ \\
n-CATT repeat & & & \\
5/5 & 46 & 30 & 16 \\
5/6 & 87 & 53 & 34 \\
$5 / 7$ & 37 & 25 & 12 \\
6/6 & 55 & 37 & 18 \\
6/7 & 55 & 39 & 16 \\
7/7 & 10 & 3 & 7 \\
5-CATT frequency & $37.2 \%$ & $36.9 \%$ & $37.9 \%$ \\
6-CATT frequency & $43.4 \%$ & $44.4 \%$ & $41.7 \%$ \\
7-CATT frequency & $19.3 \%$ & & $20.4 \%$ \\
G-173C genotype & & $18.7 \%$ & 64 \\
G/G & 170 & 74 & 29 \\
G/C & 103 & 7 & 10 \\
C/C & 17 & $23.5 \%$ & $23.8 \%$ \\
-173C frequency & $23.6 \%$ & & \\
\hline
\end{tabular}

activity score

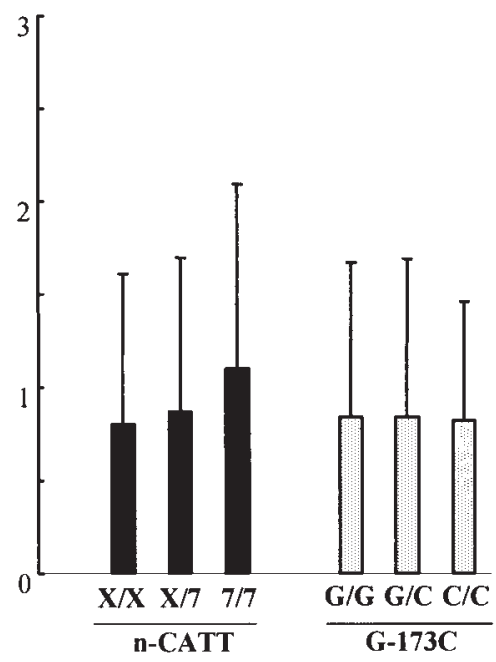

inflammation score

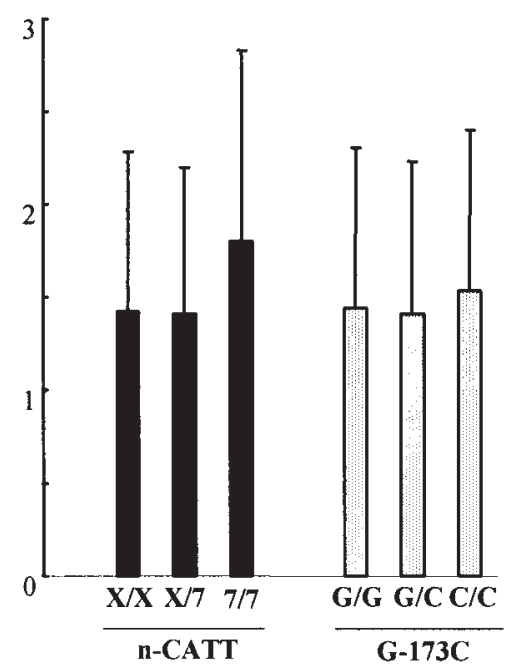

Figure 2. The association between promoter polymorphisms of the MIF gene and the inflammation or activity score. There were no significant differences among genotypes. X, 5- or 6-CATT.

promoter genotypes and the activity or inflammation score. However, we recognized the significant interaction between age and the number of 7-CATT alleles with the increase of activity and inflammation scores by ANOVA ( $\mathrm{p}=0.0067$ and $\mathrm{p}=0.0078$, respectively), so we investigated the association of MIF genotypes with the activity and inflammation scores in subjects younger than 60 years old. As shown in Fig. 3, significant relationships between the number of 7-CATT alleles and both the activity and inflammation scores were seen by linear regression analysis $(\mathrm{p}=0.0079, \mathrm{r}=0.24$; and $\mathrm{p}=0.0080, \mathrm{r}=0.24$, respectively).

\section{Discussion}

In the present study, we found a significant association between gastric mucosal atrophy and two promoter polymorphisms of the MIF gene. The $-173 \mathrm{C} / \mathrm{C}$ and $7 / 7-\mathrm{CATT}$ genotypes were significantly associated with an increased risk for the development of atrophic gastritis. Since $-173 \mathrm{C}$ was strongly associated with 7-CATT repeats, the C.7-CATT haplotype may be associated with gastric mucosal atrophy.

Infection with $H$. pylori first induces chronic superficial gastritis, which can progress to chronic atrophic gastritis, 

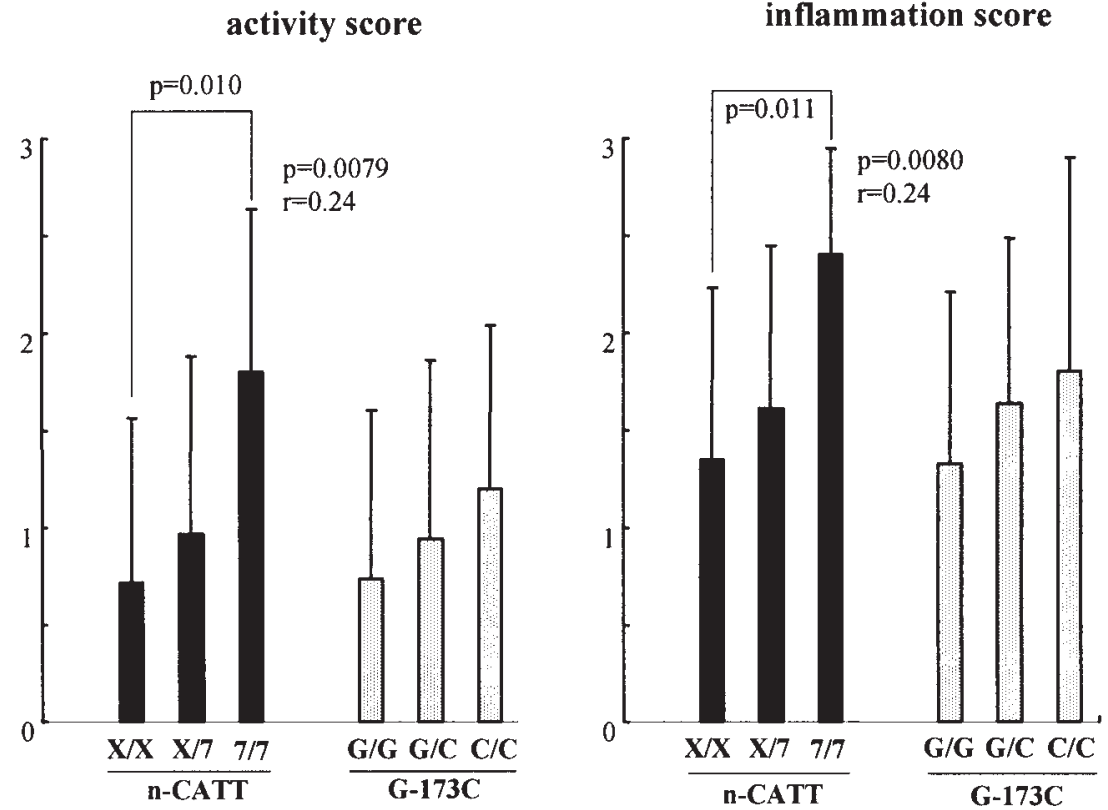

Figure 3. The association between promoter polymorphisms of the MIF gene and the inflammation or activity score in subjects younger than 60 years old. The comparison among two groups was performed by the Mann-Whitney U test, and the associations between the number of 7-CATT alleles and each score were assessed by linear regression analysis. X, 5- or 6-CATT.

Table II. Association between gastric mucosal atrophy and various risk factors.

\begin{tabular}{lcc}
\hline & \multicolumn{2}{c}{ OR $(95 \%$ confidence intervals $)$} \\
\cline { 2 - 3 } & $\begin{array}{c}\text { Unadjusted } \\
\text { odds ratio }\end{array}$ & $\begin{array}{c}\text { Adjusted } \\
\text { odds ratio }^{\mathrm{a}}\end{array}$ \\
\hline 5/5-CATT & $0.96(0.50-1.86)$ & $1.09(0.48-2.48)$ \\
$7 / 7-$ CATT & $4.47(1.13-17.7)$ & $9.69(1.29-72.5)$ \\
Male gender & $2.52(1.49-4.28)$ & $1.89(0.99-3.59)$ \\
Elder age & $1.02(1.00-1.05)$ & $1.04(1.02-1.07)$ \\
H.pylori infected & $110(15.0-804)$ & $118(15.8-888)$ \\
\hline
\end{tabular}

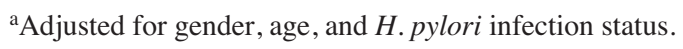

intestinal metaplasia, and dysplasia that leads toward gastric carcinoma (16). However, there are marked interindividual differences in the extent of inflammation among persons with $H$. pylori infection, so clinical consequences only develop in a small subgroup. To determine the important genetic factors, several studies concerning the association between gene polymorphisms and gastric inflammation during $H$. pylori infection were performed $(14,15,17,18)$. MIF was originally identified as an activity isolated from $\mathrm{T}$ lymphocytes that was capable of inhibiting the random migration of macrophages $(19,20)$. The human MIF cDNA was finally cloned in 1989 (21). Many studies have shown MIF to be a key modulator of many chronic and disabling human disorders, such as rheumatoid arthritis (22), sepsis (23), acute respiratory syndrome (24), and atopic diseases $(25,26)$. An important role of MIF in gastric disorders has also been shown, such as gastric inflammation (9), ulcer (27) and carcinogenesis (28). It is
Table III. Association between gastric mucosal atrophy and various risk factors.

\begin{tabular}{lcc}
\hline & \multicolumn{2}{c}{ OR $(95 \%$ confidence intervals $)$} \\
\cline { 2 - 3 } & $\begin{array}{c}\text { Unadjusted } \\
\text { odds ratio }\end{array}$ & $\begin{array}{c}\text { Adjusted } \\
\text { odds ratio }^{\mathrm{a}}\end{array}$ \\
\hline$-173 \mathrm{C} / \mathrm{C}$ & $2.77(1.02-7.50)$ & $4.60(1.05-20.2)$ \\
Male gender & $2.52(1.49-4.28)$ & $1.72(0.91-3.23)$ \\
Elder age & $1.02(1.00-1.05)$ & $1.04(1.01-1.07)$ \\
H. pylori infected & $110(15.0-804)$ & $125(16.6-951)$ \\
\hline
\end{tabular}

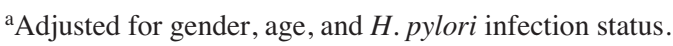

well known that a polarized $\mathrm{T}$ helper 1 immune response occurs in H. pylori infection (29). MIF directly activates or promotes cytokine expression [TNF (30), IL-2 (31), IL-8 (32) and INF- $\gamma$ (33)]. Furthermore, Xia et al have reported that $H$. pylori stimulates MIF release in monocytes and expression of MIF in gastric mucosa (9). However, there is no report regarding the association between MIF gene promoter functional polymorphisms and gastric disorders, although several studies have shown significant associations of these polymorphisms with cystic fibrosis (34), psoriasis (35), and atopic disorders (36). Therefore, we hypothesized that MIF functional polymorphisms might be associated with the development of chronic gastritis.

Promoter sequence analysis indicated that the $-173 \mathrm{C}$ allele creates a potential activator protein 4 transcription factor binding site (10), and levels of MIF expression significantly differed among G-173C genotypes in a cell type manner. Regarding CATT repeats, the 5-CATT allele was shown to 
be associated with lower basal and stimulated MIF promoter activity in vitro than 6-, 7- and 8-CATT alleles (11). Donn et al showed that increasing CATT repeats with the $-173 \mathrm{C}$ allele significantly increased the promoter activity in a $\mathrm{T}$ lymphoblast cell line (10). Thus, the -173C allele and 7-CATT seemed to promote the production of MIF, although there is no clear relationship between these polymorphisms and the transcriptional regulation of the MIF gene.

Results from our study suggested that both the 7/7-CATT repeat and the $-173 \mathrm{C} / \mathrm{C}$ genotypes, as well as $H$. pylori infection and elder age, were significantly associated with the development of gastric mucosal atrophy. Baugh et al reported the correlation of the 5/5-CATT repeat with low disease severity in rheumatoid arthritis patients (12), and Hizawa et al also reported an increased risk of non-5-CATT carriers for atopy (36). Donn et al demonstrated that the -173C-7-CATT haplotype is of importance in the susceptibility to psoriasis (35). Thus, there is no wonder that both the 7CATT repeats and the $-173 \mathrm{C}$ allele are significantly associated with the development of gastric mucosal atrophy. However, a significant relationship between the number of 7CATT alleles and inflammatory cell infiltrations was seen only in subjects younger than 60 years old. It has been shown that long-term exposure to $H$. pylori is a significant risk factor for the progression of atrophic and metaplastic gastritis $(37,38)$. In elder subjects, gastric mucosal inflammation may subside because of the progression of gastric atrophy and metaplasia. In addition, a lower serum MIF level was exhibited in elder compared to younger rats (39). Therefore, MIF may promote the gastric mucosal inflammation in younger subjects, whereas it may not in elder subjects.

In conclusion, functional polymorphisms of the MIF gene promoter may be associated with the severity of gastric mucosal inflammation in younger subjects and with the subsequent development of mucosal atrophy.

\section{References}

1. Donnelly SC and Bucala R: Macrophage migration inhibitory factor: a regulator of glucocorticoid activity with a critical role in inflammatory disease. Mol Med Today 3: 502-507, 1999.

2. Lue H, Kleemann R, Calandra T, Roger T and Bernhagen J: Macrophage migration inhibitory factor (MIF): Mechanisms of action and role in disease. Microb Infect 4: 449-460, 2002.

3. Lan HY, Yang N, Nikolic-Paterson DJ, et al: Expression of macrophage migration inhibitory factor in human glomerulonephritis. Kidney Int 57: 499-509, 2000.

4. de Jong YP, Abadia-Molina AC, Satoskar AR, et al: Development of chronic colitis is dependent on the cytokine MIF. Nat Immunol 2: 1061-1066, 2001.

5. Kumagi T, Akbar F, Horiike N and Onji M: Increased serum levels of macrophage migration inhibitory factor in alcoholic liver diseases and their expression in liver tissues. Clin Biochem 34: 189-193, 2001.

6. Calandra T, Echtenacher B, Roy DL, et al: Protection from septic shock by neutralization of macrophage migration inhibitory factor. Nat Med 6: 164-170, 2000.

7. Donnelly SC, Haslett C, Reid PT, et al: Regulatory role for macrophage migration inhibitory factor in acute respiratory distress syndrome. Nat Med 3: 320-323, 1997.

8. Roger T, David J, Glauser M and Calandra T: MIF regulates innate immune responses through modulation of Toll-like receptor 4. Nature 414: 920-924, 2001.

9. Xia HHX, Lam SK, Huang XR, et al: Helicobacter pylori infection is associated with increased expression of macrophage migration inhibitory factor by epithelial cells, T cells and macrophages in gastric mucosa. J Infect Dis 190: 293-302, 2004.
10. Donn R, Alourfi Z, De Benedetti F, et al: British Paediatric Rheumatology Study Group. Mutation screening of the macrophage migration inhibitory factor gene: positive association of a functional polymorphism of macrophage migration inhibitory factor with juvenile idiopathic arthritis. Arthritis Rheum 46: 2402-2409, 2002.

11. Amoli MM, Donn RP, Thomson W, et al: Macrophage migration inhibitory factor gene polymorphism is associated with sarcoidosis in biopsy proven erythema nodosum. J Rheumatol 29: 1671-1673, 2002.

12. Baugh JA, Chitnis S, Donnelly SC, et al: A functional promoter polymorphism in the macrophage migration inhibitory factor (MIF) gene associated with disease severity in rheumatoid arthritis. Genes Immun 3: 170-176, 2002.

13. Dixon MF, Genta RM, Yardley JH and Correa P: Classification and grading of gastritis: the updated Sydney system. Am J Surg Pathol 20: 1161-1181, 1996.

14. Arisawa T, Tahara T, Shibata T, et al: The relationship between Helicobacter pylori infection and promoter polymorphism of the Nrf2 gene in chronic gastritis. Int J Mol Med 19: 143-148, 2007.

15. Arisawa T, Tahara T, Shibata T, et al: A polymorphism of microRNA 27a genome region is associated with the development of gastric mucosal atrophy in Japanese male subjects. Dig Dis Sci 52: 1691-1697, 2007.

16. Correa P: Human gastric carcinogenesis: a multistep and multifactorial process. First American Cancer Society Award Lecture on Cancer Epidemiology and Prevention. Cancer Res 52: 6735-6740, 1992.

17. Arisawa T, Tahara T, Shibata T, Nagasaka M, Nakamura M, Kamiya Y, Fujita H, Hasegawa S, Nakamura M, Takagi T, Hirata I and Nakano H: A F240S polymorphism of proteaseactivated receptor 2 (PAR2) is not detected in Japanese population with gastro-esophageal symptoms. J Clin Biochem Nutr 39: 98-101, 2006.

18. Tahara T, Arisawa T, Shibata T, Hirata I and Nakano H: Absence of common polymorphisms of Toll like receptor 4 (TLR4): Asp299Gly, Thr399Ile in patients with gastroduodenal diseases in Japan. J Clin Biochem Nutr 40: 62-65, 2007.

19. Bloom BR and Bennett B: Mechanism of a reaction in vitro associated with delayed-type hypersensitivity. Science 153: 80-82, 1966.

20. David JR: Delayed hypersensitivity in vitro: its mediation by cell-free substances formed by lymphoid cell-antigen interaction. Proc Natl Acad Sci USA 56: 72-77, 1966.

21. Weiser WY, Temple PA, Witek-Giannotti JS, Remold HG, Clark SC and David JR: Molecular cloning of a cDNA encoding a human macrophage migration inhibitory factor. Proc Natl Acad Sci USA 86: 7522-7526, 1989.

22. Leech M, Metz C, Hall P, et al: Macrophage migration inhibitory factor in rheumatoid arthritis: evidence of proinflammatory function and regulation by glucocorticoids. Arthritis Rheum 42: 1601-1608, 1999.

23. Bernhagen J, Calandra $T$ and Bucala R: The emerging role of MIF in septic shock and infection. Biotherapy 8: 123-127, 1995.

24. Donnelly SC, Bucala R, Metz CN, et al: Macrophage migration inhibitory factor and acute lung injury. Chest 116: 111S, 1999.

25. Tulic MK, Wale JL, Holt PG and Sly PD: Modification of the inflammatory response to allergen challenge after exposure to bacterial lipopolysaccharide. Am J Respir Cell Mol Biol 22: 604-612, 2000.

26. Gereda JE, Leung DY, Thatayatikom A, et al: Relation between house-dust endotoxin exposure, type-1 T-cell development, and allergen sensitization in infants at high risk of asthma. Lancet 355: 1680-1683, 2000.

27. Huang XR, Chun HCW, Chen YX, et al: Macrophage migration inhibitory factor is an important mediator in the pathogenesis of gastric inflammation in rats. Gastroenterology 121: 619-630, 2001.

28. He XX, Yang J, Ding YW, Liu W, Shen QY and Xia HH: Increased epithelial and serum expression of macrophage migration inhibitory factor (MIF) in gastric cancer: potential role of MIF in gastric carcinogenesis. Gut 55: 797-802, 2006.

29. Bamford KB, Fan X, Crowe SE, et al: Lymphocytes in the human gastric mucosa during Helicobacter pylori have a $\mathrm{T}$ helper cell 1 phenotype. Gastroenterology 88: 70-74, 1998.

30. Calandra T, Bernhagen J, Mitchell RA and Bucala R: Macrophage is an important and previously unrecognized source of macrophage-migration inhibitory factor. J Exp Med 179: 1895-1902, 1994. 
31. Bacher M, Mets CN, Calandra T, et al: An essential regulatory role for macrophage migration inhibitory factor in T-cell activation. Proc Natl Acad Sci USA 93: 7849-7854, 1996.

32. Benigni F, Atsumi T, Calandra T, et al: The proinflammatory mediator macrophage migration inhibitory factor induces glucose catabolism in muscle. J Clin Invest 106: 1291-1300, 2000.

33. Abe R, Peng T, Sailors J, Bucala R and Metz CN: Regulation of the CTL response by macrophage migration inhibitory factor. $\mathrm{J}$ Immunol 166: 747-753, 2001.

34. Plant BJ, Gallagher CG, Bucala R, et al: Cystic fibrosis, disease severity, and a macrophage migration inhibitory factor polymorphism. Am J Respir Crit Care Med 172: 1412-1415, 2005.

35. Donn RP, Plant D, Jury F, et al: Macrophage migration inhibitory factor gene polymorphism is associated with psoriasis. J Invest Dermatol 123: 484-487, 2004.
36. Hizawa N, Yamaguchi E, Takahashi D, Nishihara J and Nishimura M: Functional polymorphisms in the promoter region of macrophage migration inhibitory factor and atopy. Am J Respir Crit Care Med 169: 1014-1018, 2004.

37. Kawaguchi H, Haruma K, Komoto K, Yoshihara M, Sumii K and Kajiyama G: Helicobacter pylori infection is the major risk factor for atrophic gastritis. Am J Gastroenterol 91: 959-962, 1996.

38. Kuipers EJ, Uyterlinde AM, Pena AS, et al: Long-term sequelae of Helicobacter pylori gastritis. Lancet 345: 1525-1528, 1995.

39. Sakamoto $\mathrm{W}$, Isomura $\mathrm{H}$, Fujie $\mathrm{K}$, et al: The effect of vitamin $\mathrm{K} 2$ on bone metabolism in aged female rats. Osteoporos Int 16: 1604-1610, 2005. 